\title{
ANALISIS FAKTOR-FAKTOR YANG MENDORONG WAJIB PAJAK RESTORAN DALAM MELAPORKAN KEWAJIBAN PERPAJAKANNYA DI KOTA MANADO
}

\author{
Yunika Handayani Pantow ${ }^{1}$, Herman Karamoy ${ }^{2}$, Sonny Pangerapan ${ }^{3}$ \\ 1, 2,3Jurusan Akuntansi, Fakultas Ekonomi dan Bisnis, Universitas Sam Ratulangi, Jl. Kampus Bahu, Manado, \\ 95115, Indonesia
}

E-mail: yukapantow@gmail.com

\begin{abstract}
Based on Local Regulation No. 2 of 2011 concerning Regional Taxes which states the procedure for setting tax rates, the procedure for collecting and paying Restaurant Tax in the City of Manado. Taxpayers are given the authority and trust to be able to calculate, pay and report their own tax amounts. This study aims to determine whether taxpayer knowledge can encourage awareness in fulfilling tax obligations in the city of Manado and what factors prevent taxpayers from fulfilling their obligations. The method used in this research is descriptive qualitative analysis. The results of this study indicate that restaurant taxpayers in the city of Manado in terms of knowing the tax regulations that apply to restaurant taxes and calculating the amount of tax to be paid in accordance with the rules of 15 speakers, paying 13 speakers, reporting 11 speakers. The Manado City BP2RD must work closely with the government in conducting socialization/counseling about collecting restaurant taxes and installing more strategic tax slogans.
\end{abstract}

Keywords: restaurant tax; taxpayers understanding; tax report

\section{PENDAHULUAN}

Menurut Mardiasmo (2011:1), pajak adalah iuran rakyat kepada kas Negara berdasarkan Undang-Undang yang dapat dipaksakan tanpa mendapat jasa timbal (kontra prestasi) yang langsung dapat ditunjukkan dan yang digunakan untuk membayar pengeluaran umum. Undang-Undang Nomor 28 Tahun 2009 tentang Ketentuan Umum dan Tata Cara Perpajakan menyebutkan bahwa wajib pajak merupakan orang pribadi atau badan, meliputi pembayaran pajak, dan pemotongan pajak. Menurut Suprianto (2011:2), peranan penerimaan pajak bagi suatu Negara sangat dominan dalam menunjang pemerintahan dan pembiayaan pembangunan. Menurut Ilyas dan Burton (2010:7), pemungutan pajak merupakan peralihan kekayaan dari rakyat kepada Negara yang hasilnya juga akan dikembalikan kepada masyarakat sehingga pemungutan pajak harus mendapatkan persetujuan dari rakyat itu sendiri mengenai jenis dan besarnya pajak yang akan dipungut. Pajak dipungut berdasarkan Undang-Undang Dasar dan aturan pelaksanaannya tanpa jasa timbal balik secara langsung dari Negara.

Menurut Rahayu (2013:138), kepatuhan dan kesadaran pemenuhan kewajiban perpajakan, tercermin dalam situasi dimana wajib pajak paham atau berusaha untuk memahami sesuai ketentuan peraturan perundang-undangan perpajakan, mengisi formulir pajak dengan lengkap dan jelas, menghitung jumlah pajak terutang dengan benar, membayar pajak yang terutang tepat pada waktunya. Berdasarkan Peraturan Pemerintah Nomor 91 Tahun 2010 tentang Jenis Pajak Daerah yang dipungut oleh Kepala Daerah atau dibayar sendiri oleh wajib pajak terhadap pajak daerah tersebut, serta beberapa jenis pajak yang harus dibayarkan sendiri oleh wajib pajak di antaranya adalah: pajak hiburan, pajak hotel, pajak restoran, pajak reklame, pajak penerangan jalan, pajak mineral bukan logam dan batuan, pajak parkir, pajak air tanah, pajak sarang burung walet, pajak bumi dan bangunan, bea perolehan hak atas tanah dan bangunan. Menurut Dama et al. (2019), jenis pajak ini 
merupakan potensi penerimaan bagi daerah, namun masih terkendala dengan kurangnya kesadaran wajib pajak akan pentingnya pemenuhan kewajiban perpajakan baik bagi negara maupun bagi wajib pajak sendiri sebagai warga negara yang baik.

Kepatuhan pajak adalah wajib pajak bersedia melakukan kewajibannya tanpa adanya paksaan dalam membayar pajak berdasarkan peraturan yang masih berlaku sehingga dapat dikatakan sebagai kepatuhan dalam persyaratan pelaporan dimana wajib pajak mengajukan, melaporkan dan membayarkan kewajibannya sesuai dengan peraturan yang berlaku (Trisnawati dan Sudirman, 2015). Tujuan penelitian ini adalah untuk mengetahui faktorfaktor apa yang mendorong pemilik restoran dalam melaporkan kewajiban perpajakannya yang berada di daerah Kota Manado.

\section{TINJAUAN PUSTAKA}

Menurut Waluyo (2013:2), pajak adalah iuran masyarakat kepada Negara yang terutang oleh yang wajib membayar menurut peraturan-peraturan umum dengan tidak mendapat prestasi kembali yang langsung dapat ditunjuk dan gunanya adalah untuk membiayai pengeluaran-pengeluaran umum berhubungan dengan tugas Negara untuk menyelenggarakan pemerintahan. Menurut Undang-Undang Nomor 28 Tahun 2007 tentang Perubahan Ketiga atas Undang-Undang Nomor 6 Tahun 1983 tentang Ketentuan Umum dan Tata Cara Perpajakan (KUP) pasal 1 butir 1 menyatakan bahwa pajak adalah kontribusi wajib kepada Negara yang terutang oleh orang pribadi atau badan yang bersifat langsung dan digunakan untuk keperluan Negara bagi sebesar-besarnya kemakmuran rakyat. Menurut Undang-Undang Nomor 16 Tahun 2009 tentang Ketentuan Umum dan Tata Cara Perpajakan pada pasal 1 ayat 1 menyebutkan bahwa pajak adalah kontribusi wajib kepada Negara yang terutang atau badan yang bersifat memaksa berdasarkan undang-undang dengan tidak mendapatkan imbalan secara langsung dan digunakan untuk keperluan Negara bagi sebesarbesarnya kemakmuran rakyat.

Menurut Mardiasmo (2018:16), pajak adalah iuran rakyat kepada kas Negara berdasarkan undang-undang dengan tidak mendapat jasa timbal yang langsung dapat ditunjukkan yang digunakan untuk membayar pengeluaran umum. Menurut Mardiasmo (2016:4), ada dua fungsi pajak, yaitu: (1) fungsi anggaran; dan (2) fungsi mengatur. Sumarsan (2012:7) menyatakan bahwa syarat-syarat pemungutan pajak adalah pemungutan pajak harus adil, pemungutan pajak tidak mengganggu perekonomian, pemungutan pajak harus efisien dan sistem pemungutan pajak harus sederhana. Menurut Resmi (2014:3), terdapat berbagai jenis pajak yang dapat dikelompokkan menjadi tiga, yaitu: (1) menurut golongan; (2) menurut sifat; dan (3) menurut lembaga pemungutannya. Menurut Kasmir (2012:250), modal kerja merupakan modal yang digunakan untuk melakukan kegiatan operasi perusahaan dan modal kerja diartikan sebagai investasi yang ditanamkan dalam aktiva lancar atau aktiva jangka pendek, seperti kas, bank, surat-surat berharga, piutang, persediaan, dan aktiva lancar.

Restoran adalah fasilitas penyedia makanan dan minuman yang dipungut bayaran, mencakup rumah makan, kafetaria, kantin, warung, bar, dan sejenisnya termasuk jasa boga/katering, pajak restoran dipungut atas pelayanan yang disediakan oleh restoran sehingga apabila setiap daerah bisa mengusahakan pendapatan atas pajak dan retribusi daerah secara maksimal daerah akan mampu memajukan setiap bidang-bidang berkaitan langsung dengan pertumbuhan ekonomi (Maramis et al., 2020). Undang-Undang Republik Indonesia Nomor 28 Tahun 2009 tentang Pajak Daerah dan Retribusi Daerah menyebutkan pajak restoran adalah pajak atas pelayanan yang disediakan oleh restoran, restoran adalah suatu penyediaan dan penjualan makan bertempat di sebagian atau seluruh bangunan termasuk penyediaan/penjualan makanan dan minuman yang diantar atau dibawa pulang serta merupakan pajak yang dikenakan atas pelayanan yang disediakan restoran dengan 
pembayaran oleh pribadi atau badan, objek pajak restoran adalah pelayanan yang disediakan oleh restoran, subjek pajak restoran adalah orang pribadi atau badan yang membeli makanan dan/atau minuman dari restoran serta wajib pajak restoran adalah orang pribadi atau badan yang mengusahakan restoran.

Dasar hukum pemungutan pajak restoran pada suatu Kabupaten/Kota adalah: (1) Undang-Undang Republik Indonesia Nomor 18 Tahun 1997 tentang Pajak Daerah dan Retribusi Daerah; (2) Undang-Undang Nomor 34 Tahun 2000 Pasal 2 Ayat 1 Pajak Restoran adalah Pajak atas Pelayanan Restoran; (3) Undang-Undang Nomor 28 Tahun 2009 Tentang Pajak Daerah dan Retribusi Daerah: (4) Peraturah Daerah Nomor 11 Tahun 2011 Tentang Pajak Restoran.; dan (5) Peraturan Pemerintah Republik Indonesia Nomor 55 Tahun 2016 Tentang Ketentuan Umum dan Tata Cara Pemungutan Pajak Daerah.

Menurut Siahaan (2010:331), pembayaran adalah jumlah uang yang harus dibayarkan oleh subjek pajak kepada wajib pajak untuk harga jual baik jumlah uang yang dibayarkan maupun penggantian yang seharusnya diminta wajib pajak sebagai penukaran atas pembelian makanan dan minuman. Undang-Undang Republik Indonesia Nomor 28 Tahun 2009 tentang Pajak Daerah dan Retribusi Daerah menyatakan bahwa tarif pajak restoran ditetapkan paling tinggi sebesar $10 \%$ dan ditetapkan dengan Peraturan Daerah Kabupaten/Kota yang bersangkutan. Hal ini dimaksudkan untuk memberikan keluasan kepada pemerintah Kabupaten/Kota untuk menetapkan tarif pajak dipandang sesuai dengan kondisi masingmasing daerah Kabupaten/Kota lainnya asalkan tidak lebih dari 10\% serta dasar pengenaan pajak adalah jumlah pembayaran yang diberikan konsumen kepada restoran. Menurut Siahaan (2016:332), besarnya pokok pajak restoran yang terutang dihitung dengan cara mengalikan tarif pajak dengan dasar pengenaan pajak. Sesuai Undang-Undang Republik Indonesia Nomor 28 Tahun 2009, perhitungan pajak restoran adalah:

$$
\begin{aligned}
& \text { Pajak Terhutang }=\text { Tarif Pajak } \mathrm{x} \text { Dasar Pengenaan Pajak } \\
& =\text { Tarif Pajak } \mathrm{x} \text { Jumlah Pembayaran yang dilakukan kepada restoran }
\end{aligned}
$$

\section{METODE PENELITIAN}

Jenis penelitian yang digunakan adalah deskriptif kualitatif. Penelitian ini bertujuan untuk memperoleh data yang akurat dan lengkap dari situasi mengenai faktor-faktor yang mempengaruhi wajib pajak dalam melaporkan kewajiban perpajakannya. Objek penelitian ini dilaksanakan di Badan Pengelola Pajak dan Restribusi Daerah Kota Manado dari bulan Januari sampai dengan selesai. Jenis data yang digunakan yaitu data kualitatif.

Sumber data yang digunakan dalam penelitian ini adalah data primer dimana data dikumpulkan dengan cara melakukan dokumentasi serta wawancara dengan pihak Badan Pengelola Pajak dan Retribusi Daerah Kota Manado serta melakukan wawancara dengan 20 pemilik restoran di Kota Manado.Analisis data dalam penelitian ini sesuai dengan analisis faktor-faktor yang mendorong wajib pajak restoran dalam melaporkan kewajiban perpajakanya, yaitu sebagai berikut: (1) mengumpulkan data yang berkaitan dengan faktorfaktor yang mendorong wajib pajak restoran dalam melaporkan kewajiban perpajakan dengan melakukan wawancara secara terbuka dengan responden serta mengumpulkan data-data realisasi penerimaan pajak restoran yang akan diteliti melalui Badan Pengelola Pajak dan Retribusi Daerah Kota Manado; (2) data yang diperoleh dari hasil wawancara dan dokumentasi di analisis, kemudian disajikan dalam bentuk catatan wawancara dan catatan dokumentasi; dan (3) mengambil keputusan atau kesimpulan berdasarkan pada pengambilan data yang telah dikumpulkan dan merupakan jawaban atas masalah penelitian ini. 


\section{HASIL PENELTIAN DAN PEMBAHASAN}

\subsection{Hasil penelitian}

Berdasarkan hasil wawancara dengan 20 narasumber yang ada menghasilkan 3 tingkat pemahaman yaitu :

1. Analisis tingkat pemahaman wajib pajak restoran pada kewajiban menghitung. Tabel 1 menunjukkan pemahaman narasumber dalam menghitung pajak yang terutang melalui pertanyaan-pertanyaan berikut: (1) apakah narasumber mengetahui tentang pemungutan pajak restoran?; (2) apakah narasumber dapat menghitung pajak sendiri?; (3) apakah kendala yang dihadapi narasumber dalam menghitung pajak?; dan (4) menurut narasumber, lebih baik menghitung pajak sendiri atau dilakukan oleh fiskus/petugas pajak?

Tabel 1. Pemahaman wajib pajak restoran pada kewajiban menghitung

\begin{tabular}{|c|c|}
\hline $\begin{array}{l}\text { Ano } \\
\text { (Eriston } \\
\text { Coffee\&Snack) }\end{array}$ & $\begin{array}{l}\text { Tidak tahu tentang pemungutan pajak restoran, tidak dapat } \\
\text { arena tidak mengerti. Lebih baik menghitung pajak sendiri" }\end{array}$ \\
\hline $\begin{array}{ll}\text { NN } & \\
\text { (RM. } & \text { Trestes } \\
\text { Café\&Resto) } & \end{array}$ & $\begin{array}{l}\text { Mengetahui tentang pungutan pajak restoran, kami menghitung pajak sendiri dan } \\
\text { dak mengalami kendala pada saat menghitung. Lebih memilih menghitung pajak } \\
\text { endiri" }\end{array}$ \\
\hline $\begin{array}{l}\text { Adry S. } \\
\text { (Red Coffee\&Eaterry) }\end{array}$ & $\begin{array}{l}\text { "Tahu tentang pungutan pajak, bisa menghitung pajak dan tidak ada kendala saat } \\
\text { menghitung pajak karena mengetahui cara menghitung pajak. Lebih memilih } \\
\text { menghitung pajak sendiri" }\end{array}$ \\
\hline $\begin{array}{l}\text { Widdhi B. } \\
\text { (RM. Mutiara) }\end{array}$ & $\begin{array}{l}\text { dantang pemungutan pajak, dan saya dapat menghitung pajak rumah makan saya } \\
\text { nemilih menghitung pajak sendiri” }\end{array}$ \\
\hline $\begin{array}{l}\text { Astrid } \\
\text { (Patong } \\
\text { Coffee\&Food) }\end{array}$ & $\begin{array}{l}\text { ungutan pajak restoran, dan bisa menghitung pajak sendiri. Tidak } \\
\text { n dalam menghitung pajak dan saya lebih memilih menghitung }\end{array}$ \\
\hline $\begin{array}{l}\text { Voni } \\
\text { (RM. Deo Gratias) }\end{array}$ & $\begin{array}{l}\text { tahu tentang pemungutan pajak restoran, sehinnga } \\
\text { umah makan saya karena tidak megerti pajak. Le } \\
\text { kus/petugas pajak. }\end{array}$ \\
\hline $\begin{array}{l}\text { Rahayu } \\
\text { (RM.Jaton Putri) }\end{array}$ & $\begin{array}{l}\text { tahu tentang pemungutan pajak restoran dan tidak dapat menghitung pajak } \\
\text { ng sendiri karena tidak tahu caranya. Saya lebih memilih menghitung sendiri }\end{array}$ \\
\hline $\begin{array}{l}\text { Jimn } \\
(\mathrm{RM}\end{array}$ & $\begin{array}{l}\text { etahui tentang pungutan pajak restoran dan saya menghitung sendiri pajak } \\
\text { makan saya tanpa ada kendala apapun. Lebih memilih menghitung pajak }\end{array}$ \\
\hline $\begin{array}{l}\text { Jimmy S } \\
\text { (RM. Kil }\end{array}$ & $\begin{array}{l}\text { idak tahu tengtang pemungutan pajak restoran, dan say } \\
\text { jak karena tidak tahu caranya. Lebih memilih pajak dihi } \\
\text { jak" }\end{array}$ \\
\hline $\begin{array}{l}\text { Erik } \\
\text { (Rm. } \\
\text { Putar'florencia") }\end{array}$ & $\begin{array}{l}\text { idak tahu tentang pemungutan pajak restoran. Tidak dapat menghitung pajak } \\
\text { utang sendiri karena tidak tahu bagaimana cara menghitung. Lebih memilih pajak } \\
\text { hitung oleh fiskus/petugas pajak" }\end{array}$ \\
\hline $\begin{array}{l}\text { Sri } \\
\text { (RM. Sopoyono) }\end{array}$ & $\begin{array}{l}\text { "Tidak tahu tentang pemungutan pajak restoran dan tidak bisa menghitung pajak } \\
\text { sendiri karena tidak tahu caranya. Lebih memilih pajak dihitung oleh fiskus/petugas } \\
\text { pajak" }\end{array}$ \\
\hline $\begin{array}{l}\text { NN } \\
\text { (RM. Ragei 21) }\end{array}$ & $\begin{array}{l}\text { "Tahu tentang pemungutan pajak restoran dan rumah makan kami bisa } \\
\text { pajak terhutang sendiri dan tidak ada kendala apapun. Lebih memilih } \\
\text { pajak sendiri" }\end{array}$ \\
\hline $\begin{array}{l}\text { NN } \\
\text { (Run }\end{array}$ & $\begin{array}{l}\text { "Tidak tahu tentang pajak restoran dan tidak bisa menghitung pajak sendiri karena } \\
\text { tidak memahaminya. Memilih menghitung pajak sendiri" }\end{array}$ \\
\hline $\mathrm{NN}$ & "Tidak tahu tentang pemungutan pajak restoran, tidak bisa 1 \\
\hline$(\mathrm{RM}$. & hitung oleh fiskus/petugas \\
\hline $\begin{array}{l}\text { Jimy } \\
\text { (Warung } \\
\text { dahsyat) }\end{array}$ & $\begin{array}{l}\text { "Tahu tentang pemungutan pajak restoran, saya bisa menghitung pajak dan tidak ada } \\
\text { kendala dalam menghitung pajak. lebih memilih menghitung sendiri pajak" }\end{array}$ \\
\hline $\mathrm{NN}$ & \\
\hline
\end{tabular}




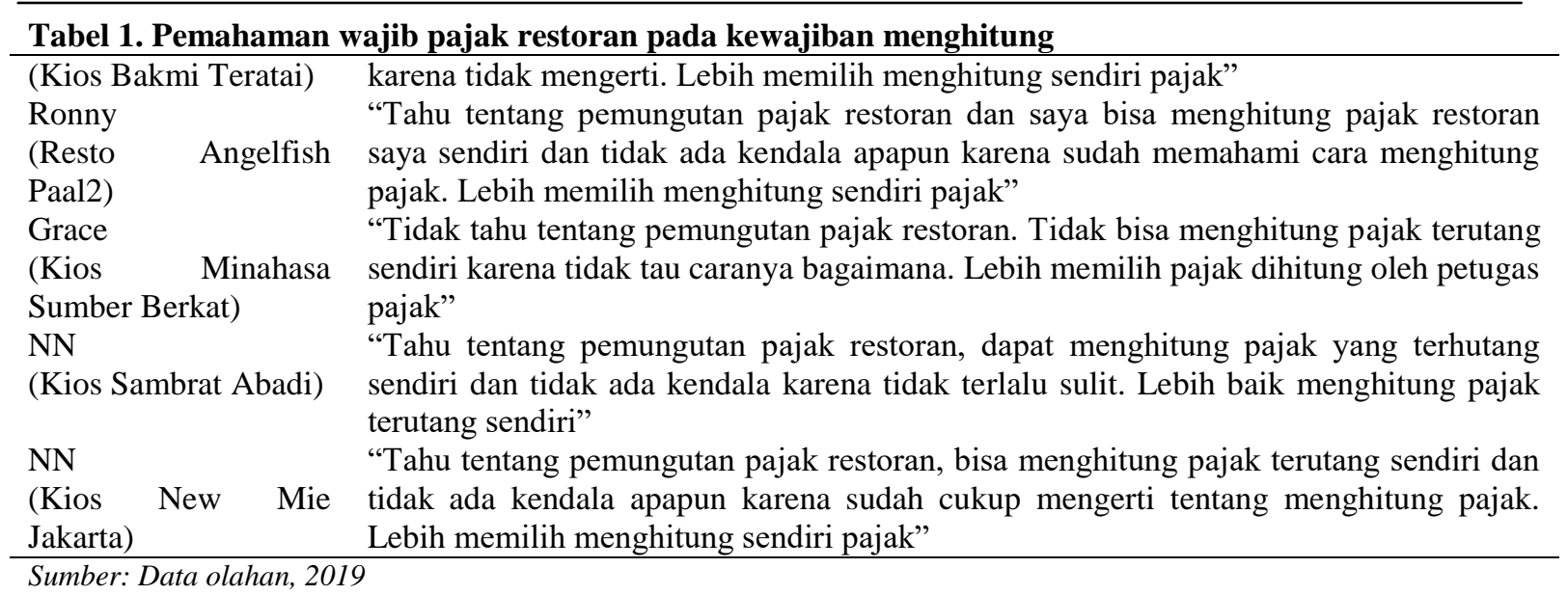

2. Analisis tingkat pemahaman wajib pajak restoran pada kewajiban membayar. Tabel 2 menunjukkan pemahaman narasumber dalam menghitung pajak yang terutang melalui pertanyaan-pertanyaan berikut: (1) kapan waktu yang tepat bagi narasumber membayar pajak?; (2) berapa persen pajak yang harus dibayarkan?; (3) apakah pajak yang dibayarkan narasumber cukup rutin?; (4) dimanakah biasanya narasumber membayarkan pajak?; dan (5) adakah kendala yang dihadapi dalam proses membayarkan pajak?

Tabel 2. Pemahaman wajib pajak restoran pada kewajiban membayar

\begin{tabular}{|c|c|}
\hline $\begin{array}{l}\text { Ano } \\
\text { (Eriston Coffee\&Snack }\end{array}$ & $\begin{array}{l}\text { "Tidak tahu kapan waktu yang tepat membayar pajak, tarif yang di kenakan sebesar } \\
10 \% \text {. Kendala yang dihadapi karena pendapatan yang tidak menentu" }\end{array}$ \\
\hline NN & "Pajak dibayarkan setiap bulannya sebesar $10 \%$ di Bank BNI, pajak dibayar secara \\
\hline $\begin{array}{ll}\text { (RM. } & \text { Trestes } \\
\text { Café\&Resto) } & \end{array}$ & rutin, dan tidak ada kendala apapun" \\
\hline $\begin{array}{l}\text { Adry S. } \\
\text { (Red Coffee\&Eaterry) }\end{array}$ & $\begin{array}{l}\text { "Pembayaran pajak tiap bulan sebesar } 10 \% \text { dan dibayar di Bank BNI secara rutin } \\
\text { tanpa ada kendala" }\end{array}$ \\
\hline Widdhi B. & "Pajak yang di bayarkan per bulan sebesar $10 \%$ dan dibayarkan pada Bank BNI. \\
\hline (RM. Mutiara) & $\begin{array}{l}\text { Pembayaran pajak cukup rutin sehingga tidak ada kendala apapun yang dialami pada } \\
\text { saat proses pembayaran" }\end{array}$ \\
\hline $\begin{array}{l}\text { Astrid } \\
\text { (Patong Coffee\&Food) }\end{array}$ & $\begin{array}{l}\text { "Pembayaran pajak tiap bulan sebesar } 10 \% \text { dan di bayarkan di Bank BNI. Tidak ada } \\
\text { kendala apapun dalam proses pembayaran, pembayaran cukup rutin" }\end{array}$ \\
\hline $\begin{array}{l}\text { Voni } \\
\text { (RM. Deo Gratias) }\end{array}$ & $\begin{array}{l}\text { "Tidak tahu kapan waktu yang tepat membayar pajak dan tarif yang berlaku. Kendala } \\
\text { yang dihadapi oleh kami yaitu kurang pengetahuan mengenai pajak" }\end{array}$ \\
\hline Rahayu & "Pajak di bayarkan per bulan sebesar $10 \%$ di Bank BNI. tidak rutin membayar pajak \\
\hline n Putri) & ken \\
\hline $\begin{array}{l}\text { Jimmy T. } \\
\text { (RM. Natasya) }\end{array}$ & $\begin{array}{l}\text { "Pajak di bayar setiap bulan di Bank BNI sebesar } 10 \% \text { secara rutin, tanpa ada kendala } \\
\text { apapun" }\end{array}$ \\
\hline $\begin{array}{l}\text { Jimmy Singkoh } \\
\text { (RM. King Fish) }\end{array}$ & $\begin{array}{l}\text { "Pajak mungkin dibayar per tahun sebesar } 10 \% \text { di kantor BP2RD. Tidak membayar } \\
\text { pajak, kendalanya yaitu karena pendapatan yang tidak pasti (kadang banyak kadang } \\
\text { sedikit)" }\end{array}$ \\
\hline $\begin{array}{l}\text { Erik } \\
\text { (Rm. } \\
\text { Putar"florencia") }\end{array}$ & $\begin{array}{l}\text { "Tidak tahu kapan waktu yang tepat, mungkin pajak di bayar pertahun sebesar } 1 \% \text { di } \\
\text { kantor BP2RD. tidak rutin membayar pajak alasannya karena tidak memahami cara } \\
\text { perhitungan pajak" }\end{array}$ \\
\hline $\begin{array}{l}\text { Sri } \\
\text { (RM. Sopoyono) }\end{array}$ & "Tidak tau kapan waktu membayar dan berapa tarif yang berlaku" \\
\hline $\begin{array}{l}\text { NN } \\
\text { (RM. Ragei 21) }\end{array}$ & $\begin{array}{l}\text { "Pajak di bayar setiap bulan sebesar } 10 \% \text {, di bayarkan ke Bank BNI. pembayaran } \\
\text { cukup rutin dan tidak ada kendala apapun" }\end{array}$ \\
\hline $\begin{array}{l}\text { NN } \\
\text { (Rumah Kopi R) }\end{array}$ & "Tidak tahu kapan waktu yang tepat dan besaran tarif yang dikenakan" \\
\hline $\begin{array}{l}\text { NN } \\
\text { (RM. Coto Iga B }\end{array}$ & "Tidak tahu kapan waktu yang tepat" \\
\hline $\begin{array}{l}\text { Jimy } \\
\text { (Warung } \\
\text { dahsyat) }\end{array}$ & $\begin{array}{l}\text { "Pajak di bayar cukup rutin tiap bulan sebesar } 10 \% \text { di Bank BNI. Pembayarannya } \\
\text { cukup rutin dan tidak ada kendala" }\end{array}$ \\
\hline
\end{tabular}




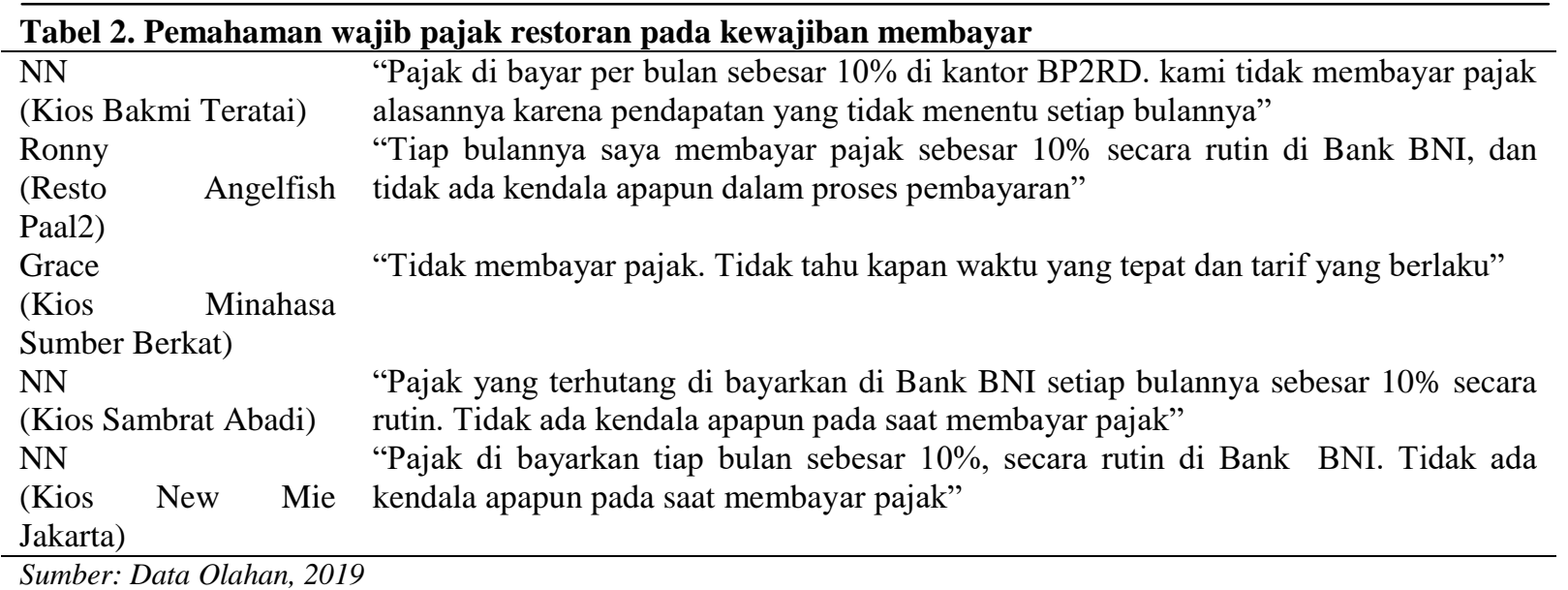

3. Analisis tingkat pemahaman wajib pajak restoran pada kewajiban melapor. Tabel berikut adalah penjelaskan pemahaman narasumber dalam melaporkan pajak yang terutang melalui pertanyaan-pertanyaan berikut: (1) apakah narasumber rutin melaporkan pajak?; (2) dimanakah narasumber melaporkan pajak yang sebelumnya telah dibayarkan?; (3) apakah narasumber mengetahui sanksi yang dikenakan jika tidak melaporkan pajak?; (4) apakah narasumber rutin mengisi SPTPD?; dan (5) menurut narasumber perlukah melaporkan pajak yang telah dibayarkan?

Tabel 3. Pemahaman wajib pajak restoran pada kewajiban melapor

\begin{tabular}{|c|c|}
\hline $\begin{array}{l}\text { Ano } \\
\text { (Eriston } \\
\text { Coffee\&Snack }\end{array}$ & $\begin{array}{l}\text { "Yang saya tau melaporkan pajak di Kantor Walikota Kota Manado. Ya, saya tahu } \\
\text { akan ada sanksi yang dikenakan. Tidak mengisi SPTPD. Menurut saya pajak yang di } \\
\text { bayarkan tidak perlu di laporkan" }\end{array}$ \\
\hline NN & "Biasanya kami melaporkan pajak di Badan Pengelola Pajak dan Retribusi Daerah \\
\hline $\begin{array}{ll}\text { (RM. } & \text { Trestes } \\
\text { Café\&Resto) } & \end{array}$ & $\begin{array}{l}\text { Kota Manado secara rutin. Ya, kami tahu akan didenda jika terlambat membayar dan } \\
\text { melaporkan pajak. Cukup rutin dalam mengisi SPTPD. Menurut saya perlu } \\
\text { melaporkan pajak yang sudah dibayarkan" }\end{array}$ \\
\hline $\begin{array}{l}\text { Adry S. } \\
\text { (Red } \\
\text { Coffee\&Eaterry) }\end{array}$ & $\begin{array}{l}\text { "Saya cukup rutin melaporkan pajak di Kantor Badan Pengelola Pajak dan Retribusi } \\
\text { Daerah Kota Manado. Ya, saya tahu akan didenda jika terlambat membayar dan } \\
\text { melaporkan pajak. Menurut saya perlu melaporkan pajak yang sudah dibayarkan. } \\
\text { Tidak rutin dalam mengisi SPTPD" }\end{array}$ \\
\hline $\begin{array}{l}\text { Widdhi B. } \\
\text { (RM. Mutiara) }\end{array}$ & $\begin{array}{l}\text { "Biasanya kami melaporkan pajak di Badan Pengelola Pajak dan Retribusi Daerah } \\
\text { Kota Manado, dan cukup rutin. Ya, kami tahu akan didenda jika terlambat membayar } \\
\text { dan melaporkan pajak. Rutin dalam mengisi SPTPD. Menurut saya pajak yang sudah } \\
\text { dibayarkan perlu di laporkan" }\end{array}$ \\
\hline $\begin{array}{l}\text { Astrid } \\
\text { (Patong } \\
\text { Coffee\&Food) }\end{array}$ & $\begin{array}{l}\text { "Saya rutin melaporkan pajak yang telah saya bayar di Kantor Badan Pengelola Pajak } \\
\text { dan Retribusi Daerah Kota Manado. Ya, saya tahu jika ada sanksi bila tidak } \\
\text { membayar dan melaporkan pajak. Cukup rutin dalam mengisis SPTPD. Menurut saya } \\
\text { perlu di laporkan jika sudah membayar pajak" }\end{array}$ \\
\hline $\begin{array}{l}\text { Voni } \\
\text { (RM. Deo Gratias) }\end{array}$ & "Tidak pernah melaporkan pajak" \\
\hline $\begin{array}{l}\text { Rahayu } \\
\text { (RM. Jaton Putri) }\end{array}$ & "Tidak pernah melaporkan pajak" \\
\hline $\begin{array}{l}\text { Jimmy T. } \\
\text { (RM. Natasya) }\end{array}$ & $\begin{array}{l}\text { "Cukup rutin dalam melaporkan pajak di Badan Pengelola Pajak dan Retribusi } \\
\text { Daerah Kota Manado. Ya, saya tau ada denda yang diterapkan oleh pemerintah. } \\
\text { Terkadang, tidak rutin mengisis SPTPD. Menurut saya pajak yang sudah dibayarkan } \\
\text { perlu di laporkan" }\end{array}$ \\
\hline $\begin{array}{l}\text { Jimmy Singkoh } \\
\text { (RM. King Fish) }\end{array}$ & "Tidak pernah melaporkan pajak" \\
\hline $\begin{array}{l}\text { Erik } \\
(\mathrm{Rm} .\end{array}$ & "Tidak pernah melaporkan pajak" \\
\hline $\begin{array}{l}\text { Putar"florencia") } \\
\text { Sri } \\
\text { (RM. Sopoyono) }\end{array}$ & "Tidak pernah melaporkan pajak" \\
\hline
\end{tabular}




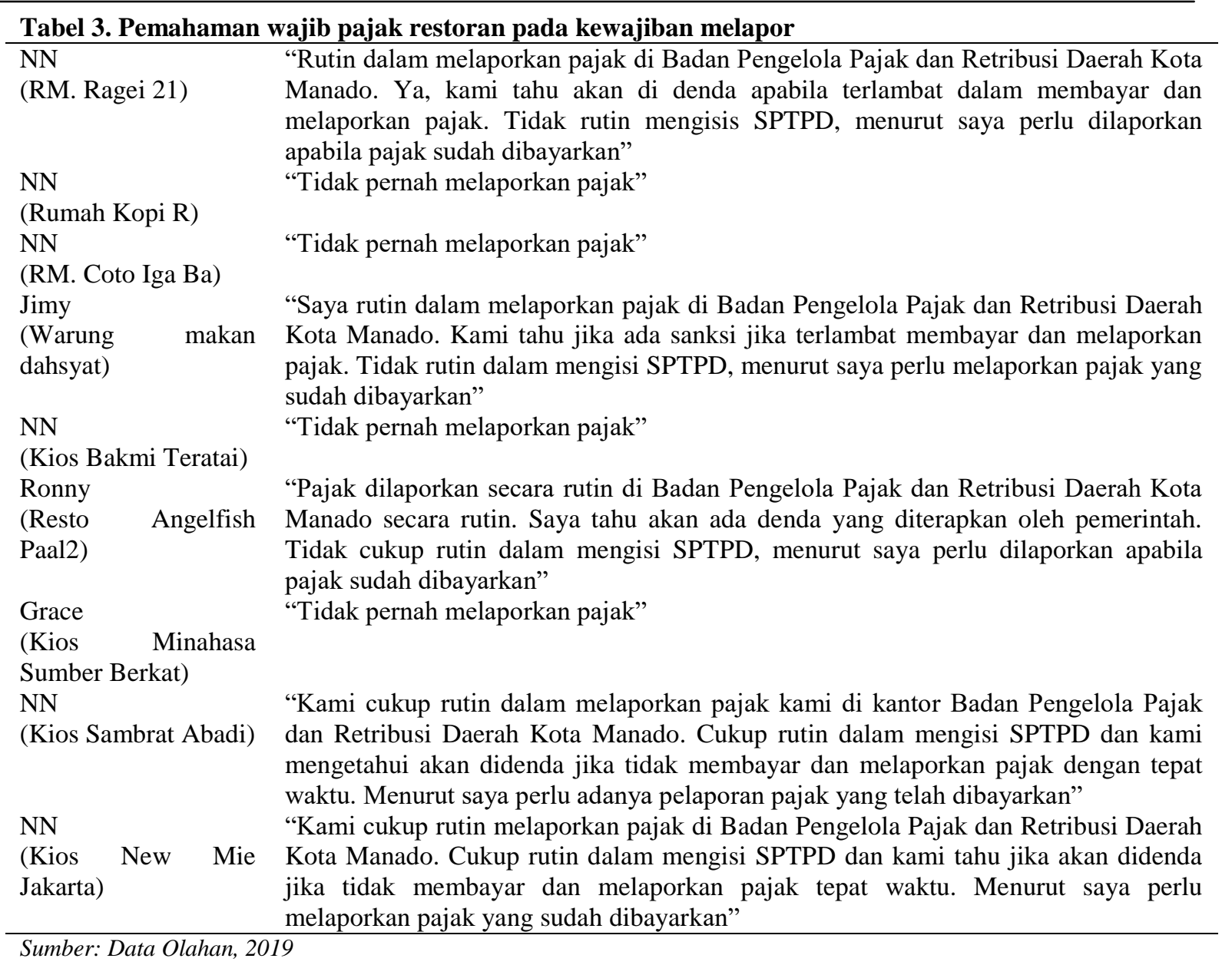

\subsection{Pembahasan}

Tingkat pemahaman wajib pajak restoran pada kewajiban menghitung. Berdasarkan Tabel 1 diketahui bahwa 15 dari 20 narasumber memahami dan mengerti dengan adanya pelaksanaan pemungutan pajak restoran, bahkan beberapa narasumber dapat menghitung sendiri pajak yang terutang tanpa bantuan dari fiskus atau petugas pajak.

Tingkat pemahaman wajib pajak restoran pada kewajiban membayar. Tabel 2 menunjukkan bahwa 13 dari 20 narasumber paham bagaimana cara membayar pajak, sedangkan yang lainnya masih kurang memahami dengan peraturan yang ada. Meskipun begitu 13 dari 20 narasumber masih lalai dan tidak taat dalam melaksanakan kewajiban perpajakannya.

Tingkat pemahaman wajib pajak restoran pada kewajiban melapor. Tabel 3 menunjukkan bahwa 11 dari 20 narasumber melaporkan pajak secara rutin dan tepat waktu yang membuktikan bahwa sebagian besar dari wajib pajak restoran paham dengan kewajiban melaporkan pajak terutang setelah dibayarkan dan beberapa wajib pajak mengetahui sanksi atau denda yang diterapkan oleh pemerintah, jika wajib pajak tidak melaksanakan kewajiban perpajakannya.

\section{KESIMPULAN DAN SARAN}

\subsection{Kesimpulan}

Berdasarkan hasil penelitian dan pembahasan maka dapat ditarik kesimpulan berikut:

1. Tingkat pemahaman wajib pajak restoran dalam kewajiban menghitung sendiri diketahui 15 dari 20 responden memahami dengan benar bagaimana menghitung pajak terutang. 
2. Tingkat pemahaman wajib pajak restoran dalam kewajiban membayar pajak hanya 13 dari 20 narasumber wajib pajak restoran memahami dengan benar bagaimana membayarkan pajak, namun masih ada wajib pajak restoran yang belum melaksanakan kewajiban perpajakan.

3. Tingkat pemahaman wajib pajak restoran dalam kewajiban melaporkan. Wajib pajak yang memahami peraturan perpajakan akan melaporkan pajak yang terutang sesuai dengan waktu yang telah ditentukan, ini juga berlaku untuk seluruh wajib pajak restoran yang ada di Kota Manado dimana wajib pajak di Kota Manado memahami tanggung jawab sebagai wajib pajak dengan melaporkan pajak secara rutin dan tepat waktu. Wajib pajak restoran di Kota Manado memahami dan mengerti akan sanksi dan denda yang dikenakan jika terlambat membayar serta melaporkan pajak yang terutang, namun beberapa wajib pajak restoran masih lalai dan tidak sadar dengan adanya pajak, terlebih bagi wajib pajak restoran atau rumah makan kecil yang tidak membayar maupun melaporkan pajak dengan rutin bahkan ada yang tidak sama sekali membayar dan melaporkan pajak yang terutang.

\subsection{Saran}

1. Badan Pengelola Pajak dan Retribusi Daerah Kota Manado sebaiknya melakukan sosialisasi atau penyuluhan mengenai pemungutan pajak restoran kepada pemilik-pemilik restoran, cafe maupun rumah makan lebih sering ataupun kunjungan dilakukan lebih sering terutama kepada pemilik restoran atau rumah makan kecil yang masih belum memahami tentang peraturan perpajakan yang berlaku.

2. Badan Pengelola Pajak dan Retribusi Daerah Kota Manado melakukan upaya memberikan pemahaman, kesadaran, dan kedisiplinan wajib pajak agar mau memenuhi kewajiban perpajakan. Hal ini dapat dilakukan dengan penyuluhan ataupun sosialisasi yang bekerja sama dengan pemerintah sekitar yang ada seperti di sekitar kecamatan ataupun kelurahan agar lebih mempermudah menjangkau restoran kecil yang ada, serta pemasangan slogan perpajakan yang lebih strategis.

3. Badan Pengelola Pajak dan Retribusi Daerah Kota Manado sebaiknya melakukan pengecekan kembali terhadap wajib pajak yang telah melakukan kewajiban mereka dalam membayarkan pajak apakah sudah sesuai dengan penghasilan yang mereka terima setiap bulannya, agar apa yang dibayarkan sesuai tanpa adanya manipulasi data yang ada.

\section{DAFTAR PUSTAKA}

Dama, A., Saerang, D. P. E., \& Gamaliel, H. (2019). Pengaruh kepemilikan NPWP terhadap kepatuhan wajib pajak pada Kantor Pelayanan Pajak Pratama Manado. Indonesia Accounting Journal, 1(2), 57-62. https://doi.org/10.32400/iaj.26638.

Ilyas, W. B., \& Burton, R. (2010). Hukum pajak: Teori, analisis, dan perkembangannya, Edisi 6. Jakarta: Salemba Empat.

Kasmir. (2012). Analisis laporan keuangan. Jakarta: PT. Raja Grafindo Persada.

Maramis, D. P., Ilat, V., \& Mawikere, L. M. (2020). Analisis penerapan pajak restoran pada penjualan (Studi kasus Rumah Makan Geprek Jo Manado), Indonesia Accounting Journal, 2(2), 87-91. https://doi.org/10.32400/iaj.27775.

Mardiasmo. (2011). Perpajakan, Edisi Terbaru 2011. Yogyakarta: Andi.

Mardiasmo. (2016). Perpajakan, Edisi Terbaru 2016. Yogyakarta: Andi.

Mardiasmo. (2018). Perpajakan, Edisi Terbaru 2018. Yogyakarta: Andi.

Peraturan Pemerintah Republik Indonesia Nomor 55 Tahun 2016 tentang Ketentuan Umum dan Tata Cara Pemungutan Pajak Daerah. 
Peraturan Pemerintah Republik Indonesia Nomor 91 Tahun 2010 tentang Jenis Pajak Daerah yang Dipungut Berdasarkan Penetapan Kepala Daerah atau Dibayar Sendiri oleh Wajib Pajak.

Rahayu, S. K. (2013). Perpajakan: Konsep dan aspek formal. Jakarta: Rekayasa Sains.

Resmi, S. (2014). Perpajakan teori dan kasus, Edisi 4. Jakarta: Salemba Empat.

Siahaan, M. P. (2010). Pajak daerah dan retribusi daerah. Jakarta: Rajawali Pers.

Siahaan, M. P. (2016). Pajak daerah dan retribusi daerah. Jakarta: Raja Grafindo Persada.

Sumarsan, T. (2012). Perpajakan Indonesia, Edisi 2. Jakarta: PT. Indeks.

Suprianto, E. (2011). Perpajakan di Indonesia. Yogyakarta: Graha Ilmu.

Trisnawati, M., \& Sudirman, W. (2015). Analisis faktor-faktor yang mempengaruhi kepatuhan wajib pajak membayar pajak hotel, pajak restoran dan pajak hiburan di Kota Denpasar, 4(12), 975-1000. E-Jurnal Ekonomi dan Bisnis Universitas Udayana. https://ojs.unud.ac.id/index.php/EEB/article/view/15361

Undang-Undang Republik Indonesia Nomor 16 Tahun 2009 tentang Penetapan Peraturan Pemerintah Pengganti Undang-Undang Nomor 5 Tahun 2008 tentang Perubahan Keempat atas Undang-Undang Nomor 6 Tahun 1983 tentang Ketentuan Umum dan Tata Cara Perpajakan menjadi Undang-Undang.

Undang-Undang Republik Indonesia Nomor 28 Tahun 2007 tentang Perubahan Ketiga atas Undang-Undang Nomor 6 Tahun 1983 tentang Ketentuan Umum dan Tata Cara Perpajakan.

Undang-Undang Republik Indonesia Nomor 28 Tahun 2009 tentang Pajak Daerah dan Retribusi Daerah.

Waluyo. (2013). Perpajakan Indonesia 1. Jakarta: Salemba Empat. 